\title{
O USO DE DOCUMENTOS HISTÓRICOS EM SALA DE AULA: IMPACTOS SOCIAIS DA CRISE DE 1929 PELAS LENTES DO FOTOJORNALISMO
}

\author{
THE USE OF HISTORICAL DOCUMENTS IN A CLASSROOM: THE SOCIAL \\ IMPACTS OF THE 1929 CRISIS BY THE LENSES OF PHOTOJORNALISM
}

Daniel Precioso ${ }^{1}$

\begin{abstract}
RESUMO: Este artigo apresenta os resultados alcançados em uma atividade pibidiana realizada na escola-campo. Trata-se de uma oficina, realizada com alunos do 90 ano do ensino fundamental, com imagens que retratam os efeitos sociais da "Grande Depressão" nos Estados Unidos dos anos 1930. A metodologia aplicada na oficina foi tomada de Paulo Knauss (2001), que teceu considerações sobre a utilização de fontes históricas em sala de aula. As fontes utilizadas na oficina foram imagens do chamado fotojornalismo. Ao apresentar os resultados alcançados, procuraremos apontar as potencialidades de tal abordagem para a formação da consciência histórica dos alunos.
\end{abstract}

Palavras-chave: Ensino de História. Fotojornalismo. Oficina

ABSTRACT: This article presents the results achieved in a pibidiana activity carried out in the school-camp. It is a workshop, held in the 9th year of elementary school, with portraits of the "Great Depression" in the United States of the 1930s. The methodology used in the workshop was taken by Paulo Knauss (2001), who made considerations on the usage of sources in the classroom. The sources used in the workshop were images of the so-called photojournalism. When presenting the results achieved, we provide notes as potentialities of approach for the formation of students' historical awareness.

Keywords: History Teaching. Photojournalism. Workshop

\section{Introdução}

Em muitas escolas brasileiras, ainda hoje, é fortemente enraizada uma concepção de ensino que faz da sala de aula um lugar de normatização e de repetição de saberes prontos e acabados. Os alunos "bem-sucedidos", nesse modelo escolar, são aqueles que melhor se adequam às normas e

\footnotetext{
${ }^{1}$ Professor Doutor da Universidade Estadual de Goiás (UEG). Este artigo foi desenvolvido no âmbito do Programa Institucional de Bolsas de Iniciação à Docência (PIBID), com fomento da CAPES. O autor coordenou, entre 2015 e 2018, o subprojeto de História do PIBID do campus Quirinópolis da Universidade Estadual de Goiás.
} 
memorizam os conteúdos "transmitidos" pelos professores, considerados autoridades supremas nos saberes de suas disciplinas. Como se não bastasse, os conteúdos curriculares, muitas vezes seguidos à risca pelos professores, são desinteressantes e distantes da realidade dos alunos (CHEVALLARD, 1997). A persistência desse modelo de ensino falido em plena "sociedade do conhecimento", aliada ao descaso da classe política na área educacional, explica os resultados negativos do Brasil em avaliações internacionais - como no último ranking Pisa, divulgado em 2016.

Em plena era digital, pode parecer redundante afirmar que não é razoável continuar a definir a função do professor como um guardião de conteúdos, responsável pela transmissão de conhecimentos. De fato, são muito antigas as críticas a esse modelo educacional. No entanto, a persistência dele torna muito atual o pensamento de pedagogos, psicólogos, filósofos e educadores que pretendiam construir uma nova escola em inícios do século passado. O construtivismo social de Vygostsky (1984) e a pedagogia da experiência de Dewey (1976) já apontavam para um modelo dialógico e para a necessidade do professor levar em consideração a vivência e as experiências prévias dos alunos. Dewey (1976), Vygotsky (1984) e Pistrak (2000), entre outros, alertavam, já nos anos 1920, que a escola não prepara para a vida, mas é a própria vida. Pistrak (2000), com seu sistema dos complexos, se insurgiu contra a compartimentação da realidade processada pelas disciplinas escolares, procurando fazer com que os currículos dialogassem com o cotidiano dos alunos, de um modo holístico. Ortega y Gasset (1989) já afirmava que a realidade não é algo dado, mas construído.

Não existe um modelo pronto e acabado capaz de dar conta de todas as realidades sociais nas quais as escolas brasileiras estão inseridas. Existem, porém, alguns direcionamentos que parecem ter se tornado um consenso entre os educadores atuais, críticos daquilo que Paulo Freire chamou de "educação bancária" (FREIRE, 1987). A principal premissa que agrega os adeptos da "educação libertadora" é a de que, na medida em que o professor torna-se mediador do processo de construção de conhecimento (o que transforma a sala de aula em um lugar de produção de saberes construídos dialogicamente), o aluno abandona a sua postura de 
passividade, de mero recebedor de conhecimentos prontos ("tábula rasa"), passando a ser "autor", agente ativo na construção e produção de saberes. Uma segunda premissa é a necessidade de centrar o processo de ensinoaprendizagem na figura do aluno, o que torna necessário respeitar as individualidades. Para cumprir esse requisito, chegamos a uma terceira premissa: é preciso mobilizar as inteligências ou aptidões pessoais dos alunos, para além da lógico-matemática e da linguística (GARDNER, 1995). É com base nesses direcionamentos, e atentos às experiências escolares embasadas nesses princípios, que o subprojeto de História do Programa Institucional de Bolsas de Iniciação à Docência (PIBID) da Universidade Estadual de Goiás (UEG), campus Quirinópolis, tem procurado nortear as suas atividades de inserção na escola-campo.

O objetivo desse estudo é apresentar os resultados práticos obtidos em uma atividade desenvolvida com alunos do $9^{\circ}$ ano do Colégio Dr. Pedro Ludovico, sediado no Município de Quirinópolis-GO. Trata-se da segunda inserção na escola-campo dos bolsistas pibidianos do Curso de História da UEG-Quirinópolis, ocorrida durante o primeiro semestre letivo de 2017. A atividade desenvolvida amparou-se na utilização de documentos históricos em sala de aula, de acordo com a proposta metodológica de Paulo Knauss (2001, p. 26-46). Ao discutir essa atividade, pretendemos dar uma pequena contribuição às pesquisas que sinalizam para a premente necessidade de reformulação da escola tradicional.

\section{A sala de aula como lugar de produção de conhecimento}

Muitos pensadores, com diferentes orientações pedagógicas, têm chamado a atenção dos educadores para o fato de que a sala de aula deve ser convertida em um lugar de produção coletiva de conhecimento. Defende-se, também, recorrentemente, que o professor deve conduzir a sua aula dialogicamente, interagindo com os alunos para concretizar o seu objetivo final: fazer do processo de aprendizagem um processo de construção de conhecimento (TERRA, 2004, p. 91-103). Uma das formas de fazê-lo - para muitos a única ou a principal delas - é fazer da pesquisa o "lugar de aprendizagem" (KNAUSS, 2001, p. 26-46). Pedro Demo (1996), 
entre os autores brasileiros contemporâneos, talvez seja um dos que mais enfatizam esse postulado. Ao compreendermos que a produção de conhecimento se realiza a partir da "relação do sujeito do conhecimento (pesquisador/investigador) com os objetos do mundo que pretende aprender" (KNAUSS, 2001, p. 29), colocamos no centro do processo de aprendizagem a pesquisa. Os alunos são, assim, incentivados a realizar "experiências", ou seja, leituras do mundo. Uma das formas de operacionalizar esse modelo, na História, é trabalhando com documentos históricos em sala de aula.

Os defensores mais aguerridos dessa proposta de indissociabilidade entre ensino de História e pesquisa, como Paulo Knauss, afirmam que esse procedimento didático dispensa a utilização do livro didático (KNAUSS, 2001 , p. 42), os quais podem ser substituídos por documentos de época. 0 procedimento instaura um modelo de ensino mais condizente com a chamada "sociedade do conhecimento" na medida em que tem por finalidade o desenvolvimento, por parte dos alunos, de "órgãos de compreensão histórica", ou seja, de mecanismos que lhes permitam realizar leituras do mundo. Ao invés de decorar conhecimentos acabados, o aluno aprende a se apropriar e a se posicionar de forma crítica diante da avalanche de informações que nos chegam, principalmente, pelas mídias e redes sociais. O desafio ao homem do século XXI é o de criar, produzir conhecimento, o que torna necessário tratar o aluno como autor - de conceitos, valores, ideias, discursos, textos, etc. (KNAUSS, 2001, p. 26-46). Por meio de um processo lógico, identificando analogias e diferenciações, o aluno aprende por meio de um processo. Obviamente, esse modelo de ensino de História faz com que o professor, e não apenas o aluno, seja um pesquisador, já que, para cada unidade de seu curso, o docente em História deverá escolher um problema que perpasse todas as fontes ou documentos escolhidos para serem analisados e debatidos em sala de aula.

Educadores, como Miguel González Arroyo (2006, p. 17-32), e especialistas no ensino de História, como Maria Auxiliadora Schmidt e Tânia Maria Garcia (2005, p. 297-308), têm chamado a atenção dos professores para o fato de que é necessário conhecer os alunos e adaptar os seus currículos à realidade dos mesmos. Schmidt, uma das principais 
divulgadoras da Didática da História de Jörn Rüsen no Brasil, desenvolveu projetos na UFPR - como o "Recriando Histórias" - nos quais propôs "atividades de captação de conteúdos", ou seja, a coleta por parte de professores e alunos do ensino básico de fontes documentais guardadas em arquivos públicos ou familiares para análise e interpretação em sala de aula, visando articular História familiar (ou a experiência vivida pelo aluno) e História ensinada na escola (ou seja, a dos manuais didáticos) (SCHMIDT; GARCIA, 2005, p. 307). Como os manuais didáticos apresentam um conteúdo impessoal e anônimo, os alunos de História não conseguem, por conta própria, conectar as suas experiências de vida com a História ensinada. Disso resulta que a História, enquanto disciplina, aos olhos dos alunos do ensino básico, consiste em um conhecimento quase enciclopédico, que se memoriza, mas que não pode ser utilizado no cotidiano, na vivência diária.

Para a formação da "consciência histórica crítico-genética" (RÜSEN, 1992) - os dois estágios mais complexos da compreensão histórica que permitem que nos posicionemos criticamente frente ao passado e atuemos na conduta do presente - é necessário fazer com que o aluno articule a sua História de vida com a História contada nos manuais didáticos. Tanto o projeto "Recriando Histórias", de Schmidt \& Garcia (2005, p. 297-308), quanto a proposta de Knauss (2001, p. 26-46) de utilização de documentos históricos em sala de aula apontam caminhos para atingir o grau de consciência histórica almejado. O subprojeto de História do PIBID da UEGQuirinópolis tem atuado nessas duas frentes, mas, por ora, pretendemos apresentar os resultados da atividade desenvolvida com base na proposta de Knauss.

\section{O uso de documentos em aulas de História}

Na coletânea Repensando o ensino de História, o historiador Paulo Knauss (2001, p. 26-46) apresentou uma metodologia para o emprego, por parte do professor de História, de documentos históricos em sala de aula. ${ }^{2} \mathrm{~A}$

\footnotetext{
2 Em se tratando de documentos escritos, obviamente, o professor deverá adequar a(s) fonte(s) utilizada(s), tendo em vista o público-alvo. A transliteração (atualização da grafia),
} 
base do método é a concepção dialógica da produção do conhecimento e a pesquisa/investigação como processo de aprendizagem. O professor deve selecionar uma fonte histórica produzida durante o período que irá abordar em sala de aula, propondo aos alunos "exercícios de leitura". O objetivo será "desmontar o documento", ou seja, explicitar o lugar de quem enuncia, a quem se dirige o discurso, e as suas formas de recepção (PEREIRA NETO, 2001, p. 143).

O aluno deverá colocar-se no lugar de quem produz o documento (por uma espécie de "compreensão empática") e descodificar o enunciado, compreender os argumentos do autor do documento, posicionando-se criticamente (de modo a reelaborar o enunciado, tornando-se, assim, autor) (TERRA, 2004, 91-103). Essa reelaboração poderá ser feita por meio da construção de conceitos que, segundo Knauss (2001, p. 26-46), são "possibilitadores de uma leitura do mundo". A palavra do professor, "orientador" ou "animador" desse processo de aprendizagem, deve ser a última; afinal, é o aluno que deve "ler o mundo" (o veículo é o documento histórico). Ao cabo, o aluno poderá montar uma espécie de "apostila" ou portfólio, contendo documentos intercalados com textos de sua autoria. Evidentemente, por "texto" não compreendemos apenas os escritos dos alunos, mas, também, desenhos, músicas, peças teatrais ${ }^{3}$ e etc.

Embora o objetivo final possa ser o "conteúdo conceitual", ou seja, tornar inteligíveis fatos históricos (em sentido amplo) por meio do estabelecimento de relações de causa e efeito, o professor deverá mobilizar os conceitos do cotidiano do aluno para a construção do conhecimento histórico. Portanto, em primeiro lugar, realiza-se a compreensão do processo histórico para, somente depois, nomeá-lo (ou conceituá-lo). Por exemplo, ao abordar as primeiras trocas realizadas entre os invasores portugueses da América e as populações nativas, almejam-se as formas e os sentidos dessas transações, o que tornará a palavra "escambo" apenas um acréscimo ao vocabulário do aluno. Assim, privilegia-se a reflexão, o criticismo, ao invés da memorização de saberes prontos.

sobretudo das abreviações, deverá ser realizada para facilitar a leitura e a interpretação dos documentos.

${ }^{3}$ As encenações ou peças teatrais podem, aliás, ser muito eficientes para a transposição dos alunos à época e ao lugar em que as fontes históricas foram produzidas, sendo uma forma de efetivar a "compreensão empática". 
O professor poderá, ainda, selecionar dois documentos, para uma mesma aula, que possuem visões distintas sobre o mesmo objeto do conhecimento. Desse modo, o aluno poderá confrontar perspectivas distintas, o que incentiva seu posicionamento crítico diante do que se discute em sala de aula, traço essencial para a formação da consciência histórica - e não apenas frente ao conteúdo apresentado na escola, mas, também, fora dela (nas mídias, nos museus, nos teatros e etc.). Por fim, essa proposta também permite uma avaliação formativo-contínua, ou seja, que se volta para o processo de aprendizagem, para o caminho trilhado pelo aluno durante esse processo, perdendo a "prova escrita" o seu caráter de exclusividade (KNAUSS, 2001, p. 26-46).

\section{Estudando a "Grande Depressão" através do fotojornalismo dos anos 1930}

Os pibidianos de História da UEG, campus Quirinópolis, em atividade realizada na escola-campo sobre a Crise de 1929 (conteúdo programático do $2^{\circ}$ bimestre de 2017 nas turmas de $9^{\circ}$ ano do ensino fundamental), aplicaram a metodologia proposta por Paulo Knauss (2001, p. 26-46) para o uso de documentos históricos em sala de aula. Para tanto, nos encontros preparatórios, realizados na universidade, vários documentos escritos e iconográficos foram selecionados previamente para a elaboração das sequências e planejamentos pedagógicos. Dentre os documentos selecionados, destacam-se as imagens de Dorothea Lange (1895-1965), influente fotógrafa documental e fotojornalista norte-americana conhecida por seus retratos da Grande Depressão para a Farm Security Administration (FSA). Suas imagens ajudaram a humanizar as consequências da Crise de 1929 e influenciaram o desenvolvimento da fotografia documental.

A Farm Security Administration (FSA) se tornou um mecanismo para despertar a sociedade, devido ao sentimento crítico de denúncia presente em fotógrafos como Dorothea Lange e Walker Evans, que fizeram parte da primeira turma de profissionais do projeto. Esses profissionais conseguiram driblar alguns dos obstáculos colocados pelo governo durante o trabalho em campo, alcançando maior liberdade em suas fotos, o que já sinalizava os 
primeiros indícios do que se tornaria, mais tarde, o fotodocumentarismo. A intenção dos pioneiros da fotografia documental era dar um testemunho, mostrar aos que não vivenciaram a Crise de 1929 as consequências da "Grande Depressão". As imagens tinham uma clara intenção de denúncia. Pretendia-se atingir a opinião pública, como registrou Dorothea Lange, conscientizando as pessoas sobre as profundas consequências da Crise de 1929 sobre a população norte-americana (CURTIS, 1986, p. 1-20).

Filha da segunda geração de uma família de imigrantes alemães com o sobrenome Margaretta Nutzhorn, Dorothea passou a usar o nome de solteira da mãe aos 12 anos, quando seu pai abandonou a família. Esse foi um dos dois incidentes traumáticos que marcaram sua infância. O outro deles consistiu na contração de poliomielite aos sete anos, o que a deixou com a perna direita enfraquecida e a fez mancar pelo resto da vida. Essa dificuldade de locomoção não impediu a realização do seu trabalho com as câmeras, nem arrefeceu a sensibilidade com que imortalizou momentos marcantes da História norte-americana, como, por exemplo, a evacuação forçada de japoneses americanos a campos de realojamento após o ataque a Pearl Harbor durante a Segunda Guerra Mundial (CURTIS, 1986, p. 1-20).

Lange aprendeu fotografia com Clarence $\mathrm{H}$. White, na Columbia University (Nova Iorque), e logo começou a trabalhar como aprendiz em diversos estúdios da cidade, como o Arnold Genthe. Em 1918, mudou-se para São Francisco, onde abriu um estúdio de retratos e morou pelo resto de sua vida. Com a Crise de 1929, Lange tirou sua câmera do estúdio para registrar a situação das ruas. As imagens captadas dos desabrigados chamaram a atenção de outros fotógrafos, o que a levou a trabalhar na Ressettlement Administration (RA), depois chamada de Farm Security Administration (FSA), uma instituição criada com o objetivo de combater a pobreza rural, uma das principais consequências da Grande Depressão (CURTIS, 1986, p. 1-20).

Nas últimas décadas de sua vida, Lange sofreu de diversos problemas de saúde. Faleceu em 1965. Em 2006, uma escola foi batizada em sua homenagem em Nipomo, na Califórnia, perto do local onde foi registrada a "Migrant Mother", a sua foto icônica. Esse foi um dos documentos escolhidos pelos pibidianos para analisar os efeitos sociais da Crise de 1929. 
Embora a "Migrant Mother" esteja presente em capítulos de muitos livros didáticos referentes à Grande Depressão, quase sempre aparece como mera ilustração. Na perspectiva de muitos autores de livros didáticos, os aspectos políticos e econômicos são privilegiados em detrimento das questões sociais. Foi visando suprir essa lacuna e abordar os efeitos sociais da crise na população mais vulnerável, que selecionamos "Migrant Mother", fotografia produzida na Califórnia, por Dorothea Lange, em 1936 (BASTOS, 2014, p. 139).

Roland Barthes analisou a fotografia de imprensa, avaliando a relação entre texto e imagem no fotojornalismo. Como observou Barthes (1962), a fotografia - como registro análogo (analogon) do real - possui uma estrutura meramente denotativa, ou seja, é frágil em termos conotativos. Barthes identifica, portanto, uma clara primazia do texto sobre a imagem na mensagem final a ser transmitida pelo jornalista. Não obstante, aprofundando a reflexão, conseguimos atingir o significado fotográfico, uma vez que as fotografias de jornais sempre trazem consigo seu referente (BARTHES, 1984, p. 16) - como no caso das fotos produzidas durante a grande depressão econômica norte-americana. Para superar essa fragilidade conotativa das imagens, Barthes propôs uma análise da: conotação perceptiva (análise da imagem em sua "metalinguagem interior" ou coincidente com os planos de conotação da linguagem); conotação cognitiva (leitura atrelada às informações sobre o mundo do leitor, sobre os estereótipos de sua formação sociocultural); e conotação ideológica (identificação das ideologias políticas não presentes na própria imagem) (BARTHES, 1984). ${ }^{4}$

A análise desse tipo de documento requer, portanto, atenção, uma vez que as fotografias são impregnadas de significados visíveis ou subentendidos. Tais especificidades dificultam o uso contínuo das imagens enquanto documento, sobretudo nos livros didáticos, tendo como agravante a disposição das fotografias desvinculadas do contexto histórico e mesmo a falta de conhecimento do professor na condução da análise imagética com os alunos em sala. Como assinalado anteriormente, o professor não deve

\footnotetext{
${ }^{4}$ A busca de conotações exteriores à própria imagem foi a principal crítica desferida contra Barthes (BECEYRO, 1980).
} 
ser entendido como detentor do conhecimento, mas como um agente que direciona a discussão. Na atividade proposta, o professor municia os seus alunos com as "armas" (ferramentas analíticas) necessárias para a "desconstrução" da imagem, com vistas à elucidação dos processos que envolveram a sua produção (autoria, intencionalidade, relação emissor/receptor).

Figura 1 - "Migrant Mother" (1936)

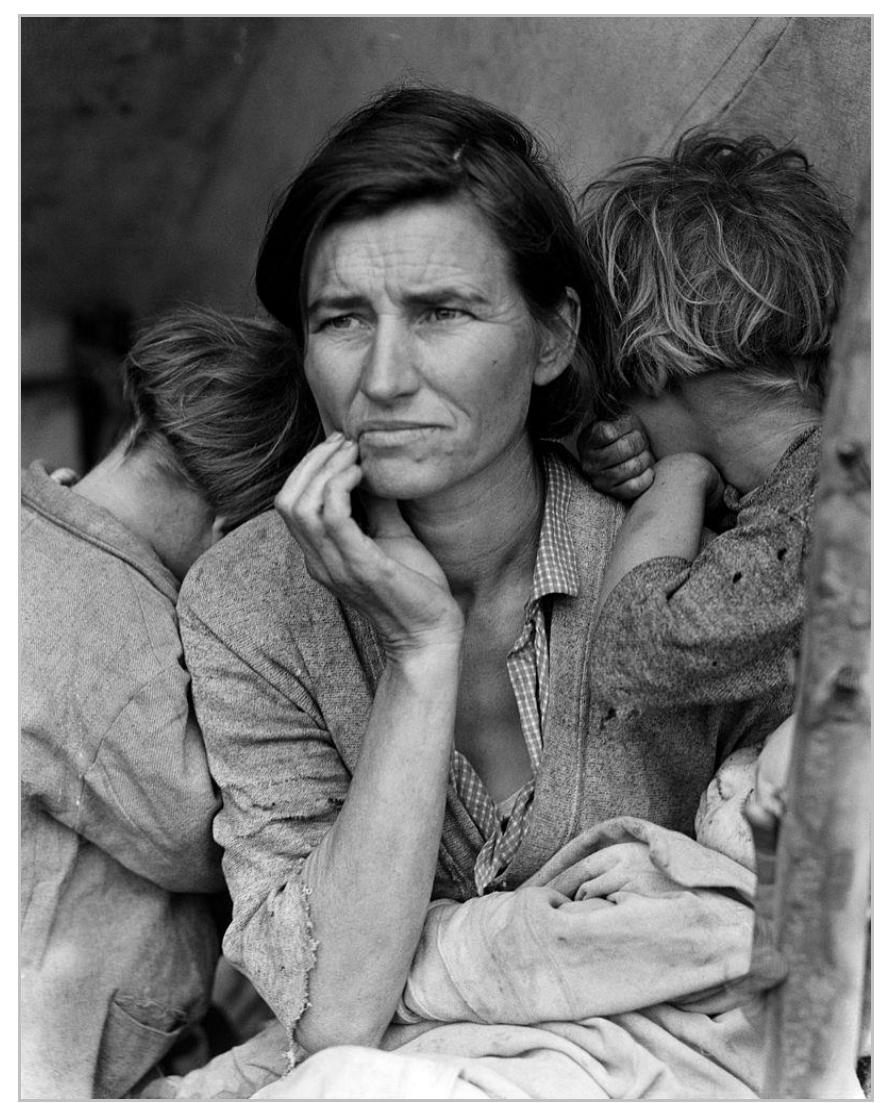

Fonte: Bastos (2014, p. 139).

Foto de Dorothea Lange (Florence Owens Thompson)

Valendo-se de sua sensibilidade para registrar momentos únicos na História, Dorothea Lange captou com sua máquina os efeitos da crise de 1929, nos Estados Unidos. Em uma zona rural californiana, Lange encontrou a protagonista de "Migrant Mother", em 1936. Como resultado desse trabalho, foram feitas seis exposições da senhora Owens segurando um bebê: com dois de seus filhos em pé, um de cada lado dela, as cabeças inclinadas, os rostos desviados da câmera. Este close-up direciona nossa 
atenção para o comportamento passivo da mulher malvestida e prematuramente envelhecida, olhando pensativa para longe da câmera. Como a própria fotógrafa dizia - "Embora talvez haja uma esfera de ação em que a fotografia não pode nos dizer nada mais do que o que vemos com nossos próprios olhos, existe outra que nos prova o quão pouco nossos olhos nos permitem ver" (CURTIS, 1986, p. 1-20).

Em "Migrant Mother", podemos captar as sensibilidades, as sensações e as emoções, assim como aquilo que não está explícito na fisionomia da protagonista. Cabe ao historiador conduzir a pesquisa por meio de uma descrição densa e reconhecer no meio social essas especificidades que se manifestam no cotidiano. Nas palavras de Sandra J. Pesavento (2003, p. 58-9), "sensibilidades resgatam histórias individuais ou coletivas. $\mathrm{Na}$ experiência histórica as pessoas resgatam emoções, sentimentos, ideias, temores ou desejos, a tradução sensível que pode ser historicizada e a sociabilidade para os homens de determinada época".

Essa abordagem, influenciada pela antropologia interpretativa de Clifford Geertz, pode ser aplicada ao trabalho que Lange desenvolveu no período da grande depressão norte-americana de 1929 e nos seus reflexos durante os anos 1930.

A atividade realizada na escola-campo teve a seguinte sequência: 1 ) a imagem de Lange foi apresentada aos alunos, que formaram grupos de discussões mediadas por um ou dois bolsistas pibidianos; 2) algumas informações complementares - como a autoria da imagem e a contextualização do ano de sua produção -, além de informações acerca das pessoas fotografadas, foram preliminarmente apresentadas/debatidas com os alunos; 3 ) instaurou-se um dialogismo, que culminou na percepção (por parte dos alunos) da situação social de muitas famílias afetadas pela Crise de 1929 - no caso da foto de Langue, na zona rural nos Estados Unidos durante a década de 1930.

Uma das informações que mais impressionou os alunos foi a de que a mulher fotografada tinha apenas 32 anos, já que a maior parte deles afirmou que ela aparentava ser uma senhora com, aproximadamente, 50 anos. Outro fato que gerou discussão nos grupos foi a passividade da mulher diante da fotógrafa que, nas palavras de Lange, não teria feito 
nenhuma objeção ou questionamento ao ser fotografada. Os alunos compreenderam, assim, que esse estado de prostração refletia a tristeza e a falta de perspectiva que assolava grande parte da população dos Estados Unidos e de muitos países da Europa durante a crise.

Ao longo da execução da atividade, os alunos também se depararam com outras informações extrínsecas à imagem, como, por exemplo, a de que a mulher e seus filhos viviam de legumes congelados e da caça de pequenos animais nas zonas rurais circundantes à sua habitação. Munidos dessas informações (explícitas, implícitas e adicionais), foram introduzidas algumas problemáticas sobre a Crise de 1929 com o objetivo de incentivar os alunos a realizarem leituras da Grande Depressão, a partir da imagem de Lange. Por fim, os alunos produziram relatos (imagéticos ou textuais) acerca da imagem, relacionando-a com a Crise de 1929.

Para tratar dos aspectos sociais da crise, foram apresentadas, ainda, outras imagens produzidas nos anos 1930. A fotografia "An Afro-American family near Southern Pines, North Carolina" (foto do MPI de 1935), além de representar os problemas sociais, introduz a questão racial. A partir dessa imagem, os alunos puderam questionar quais os reflexos da Grande Depressão sobre a população negra do sul dos Estados Unidos. Para além dos semblantes apáticos - como o da protagonista da foto de "Migrant Mother" - os negros sulistas foram fotografados diante de seu paupérrimo casebre de madeira. Os alunos puderam compreender que os efeitos da crise foram, ainda, mais dramáticos sobre a população negra que, além de sofrer os efeitos sociais da crise, também padecia os efeitos nefastos da segregação racial. 
Figura 2 - "An Afro-American family near Southern Pines, North Carolina" (1935)

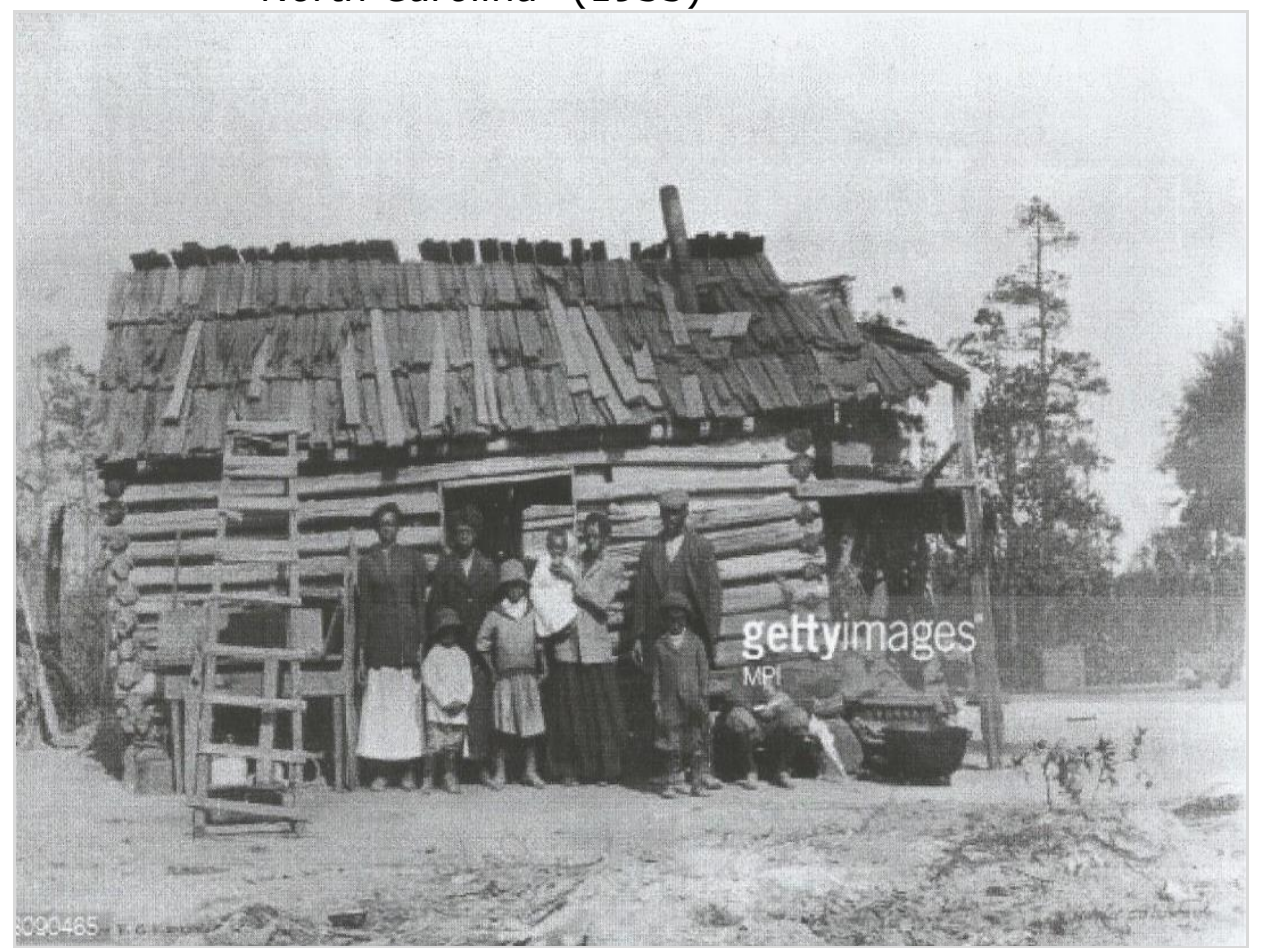

Fonte: $\quad$ https://www.gettyimages.ie/detail/news-photo/an-africanamerican-family-near-southern-pines-north-news-photo/3090465

Foto de Dorothea Lange

Foi, também, apresentada aos alunos a fotografia intitulada "A Family in Pittsburgh County" (1938), igualmente de autoria de Dorotheia Lange, que representa uma família de Oklahoma forçada a deixar sua casa durante a Grande Depressão. Na imagem, em primeiro plano, observamos o chefe de família arrastando seus poucos pertences (com um de seus filhos sentado sobre os objetos carregados). Ao fundo, vê-se a mãe com dois filhos e uma mulher que leva um carrinho de bebê. Todos os agentes representados se encontravam em uma estrada que cortava a zona rural. 
Figura 3 - "A Family in Pittsburgh County" (1938)

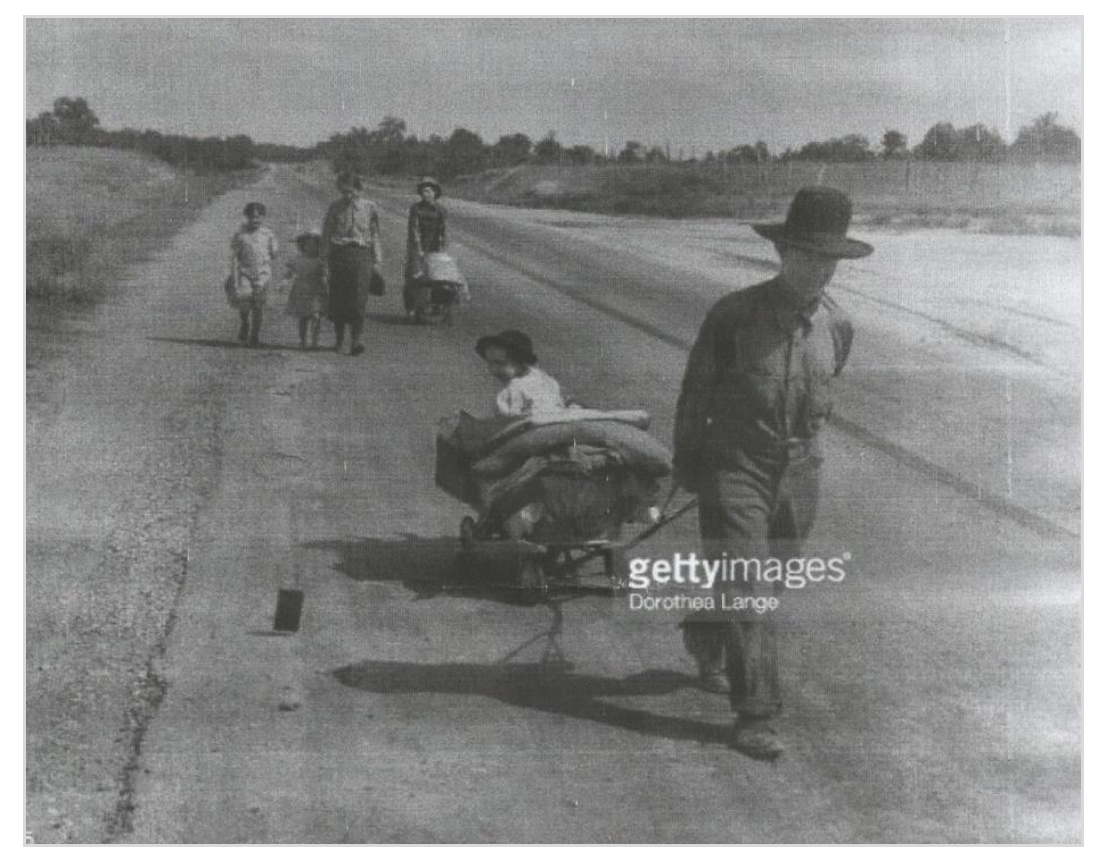

Fonte:https://www.kstate.edu/english/nelp/childlit/1930s/lange fam hwy.html

\section{Foto de Dorothea Lange}

A última imagem apresentada aos alunos retratava os "Gastonia Cotton Mill Crushers" (Carolina do Norte), que foram despejados em 1929. $\mathrm{Na}$ imagem captada pelas lentes de Bethmann, observamos William Trutt e sua família sendo despejados. A grande pobreza do casal e filhos pode ser vislumbrada nos semblantes desgastados do casal. Todos estão maltrapilhos e ao redor encontram-se os parcos e humildes pertences familiares. 
Figura 4 - "Gastonia Cotton Mill Crushers" (1929)

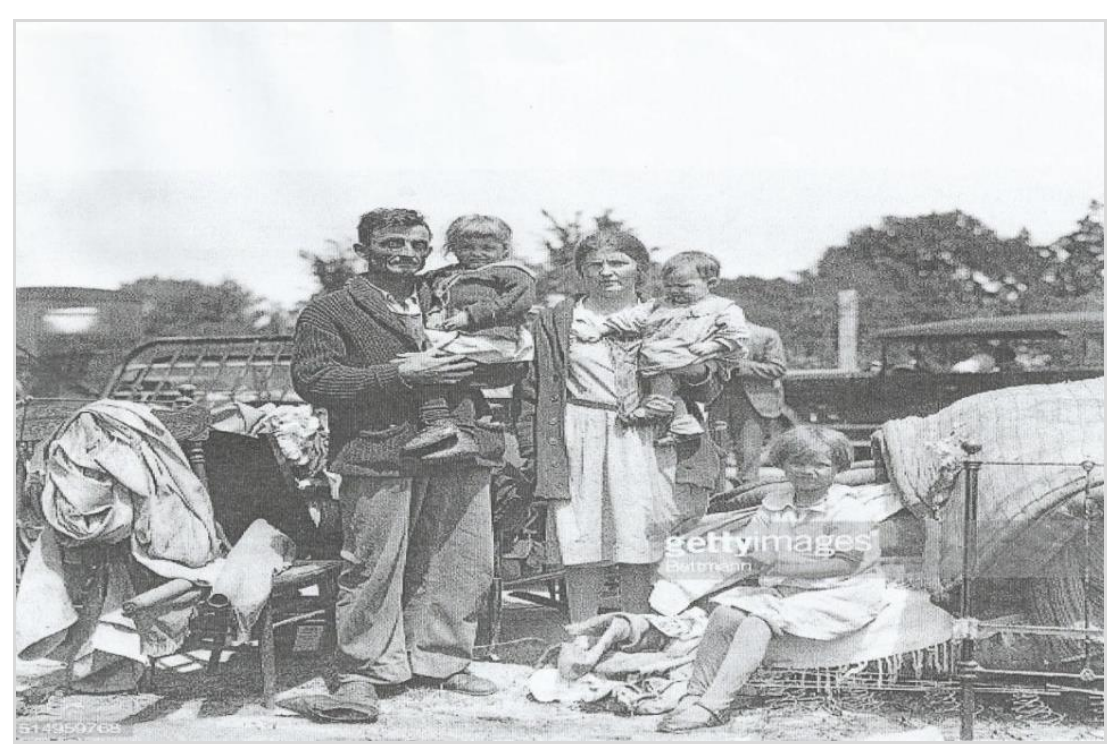

Fonte:https://www.kstate.edu/english/nelp/childlit/1930s/lange fam hwy.html Foto: Theobald von Bethmann

Nos relatórios produzidos a partir da análise das imagens acima, os alunos do 90 ano da escola-campo abordaram os reflexos sociais da Grande Depressão. Um dos alunos desenhou um tríptico, retratando, respectivamente, o estado de bem-estar social após a Primeira Guerra Mundial, a crise de superprodução e os reflexos sociais (demissões em massa) posteriores à Crise de 1929. 
Figura 5 - A crise de 1929

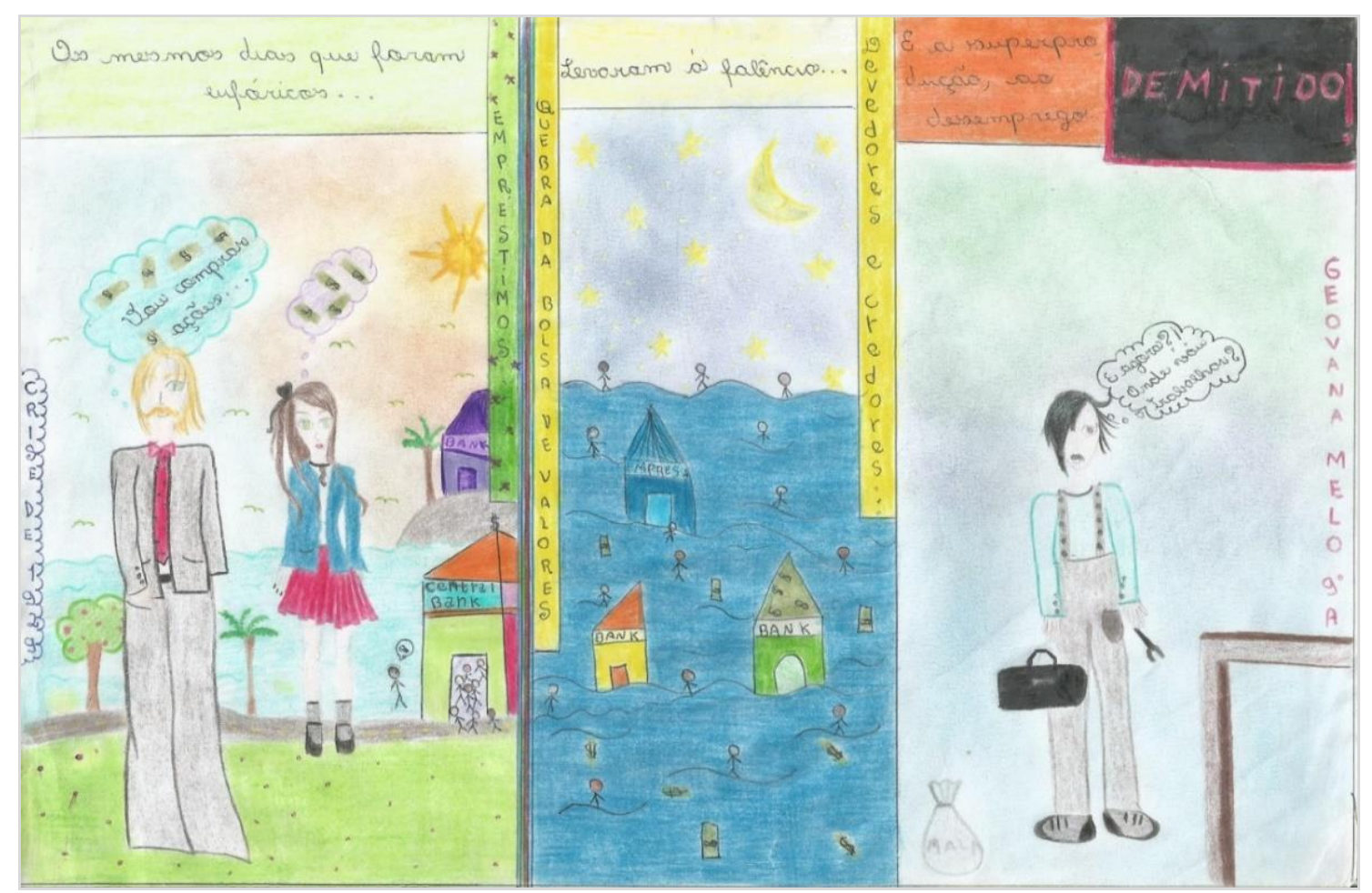

Fonte: Relatório apresentado por aluno da escola-campo

Em outro relatório, demonstrando uma análise processual-conjuntural da História norte-americana do Entre guerras, a mesma sucessão de conjunturas econômicas acima é abordada em forma de um poema intitulado "A crise":

Estados Unidos era o maior

Lá tinha o melhor

A euforia reinava lá

Mas depois algo iria mudar

Pois algo estava prestes a aparecer

E mudanças iriam acontecer

$\mathrm{Na}$ época tudo era diferente Não havia nada que impedisse

Que a alegria em todos visse

Mas depois houve um acidente

E toda euforia se quebrou

E uma crise levou

Uma potência rica

Virou uma potência que se quebrou

Fome, desemprego, tristeza e dor

Se esparramou, mas não faltou amor

Eles tinham esperança

Vontade de que suas crianças

Pudessem ter o melhor 


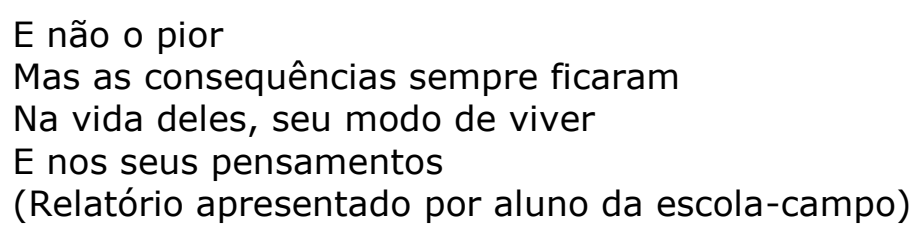

As mudanças de conjunturas, abordadas no poema, foram acompanhadas de duas imagens: na primeira (na parte superior da página, ao lado dos versos que retratam os anos de criação do american way of life), observamos uma mulher bem vestida; abaixo, ao lado dos versos que falam de fome, desemprego e tristeza, é representada uma mulher chorando com uma filha no colo.

\section{Palavras finais}

Os dois relatórios produzidos pelos alunos do 90 ano da escolacampo, acima analisados, apontam para a construção do conhecimento e da consciência histórica em sala de aula. A partir da análise de imagens, descodificação de ícones e análise contextual da produção fotojornalística, os alunos puderam captar a mensagem dos fotógrafos, discutir suas intenções e, por fim, realizar uma leitura, produzindo relatórios (imagéticos ou textuais). A atividade atingiu o objetivo almejado: estimular a reflexão dos educandos e promover um espaço de pesquisa/oficina em que o alunato se torna "autor", produtor de conhecimentos. Nesse sentido, embora informações sobre o contexto de produção da imagem tenham sido trazidas à baila, procurou-se estimular a criatividade dos alunos, deixando-os livres para proporem leituras e identificarem novos significados intrínsecos às imagens analisadas. Portanto, os bolsistas pibidianos e a professora supervisora não visaram conduzir os alunos à dedução de constatações premeditadas; ao invés disso, procuraram induzi-los à construção autônoma de significados (previstos e imprevistos), mediada apenas, é claro, pelo crivo da crítica documental.

Tendo em vista as "múltiplas inteligências" (GARDNER, 1995), os alunos puderam escolher os temas/conteúdos a serem abordados, assim como a forma de apresentação (textual, imagética, poética, etc.). Por vezes, texto e imagem foram conjugados na confecção dos relatórios, como 
no caso do poema reproduzido acima (que também trouxe imagens que auxiliaram no processo de construção de sentido). Com essa atividade pibidiana, procuramos transformar a sala de aula em oficina/laboratório de pesquisa em História, alçando os alunos a agentes ativos no processo de construção de conhecimento. Por fim, na esteira de Knauss (2001, p. 2646), reiteramos as potencialidades da utilização de documentos históricos em sala de aula, despindo-os de seu caráter imanente e ou meramente ilustrativo (como geralmente aparecem em manuais didáticos).

\section{Referências}

ARROYO, Miguel González. Formar educadoras e educadores de jovens e adultos. In: SOARES, Leôncio (org.). Formação de educadores de jovens e adultos. Belo Horizonte: Autêntica, 2006. p. 17-32.

BARTHES, Roland. A câmara clara: nota sobre a fotografia. Rio de Janeiro: Nova Fronteira, 1984.

BASTOS, Ana Rita. A fotografia como retrato da sociedade. Sociologia:

Revista da Faculdade de Letras da Universidade do Porto, Porto, PT, v. 28, p. 127-143, 2014.

BECEYRO, Raúl. Ensayos sobre fotografia. Cidade do México: Arte y Libros, 1980.

CHEVALLARD, Yves. La transposición didáctica: del saber sábio al saber a ser ensinado. Buenos Aires: Aique, 1997.

CURTIS, James C. Dorothea Lange, migrant mother, and the culture of the great depression. Winterthur Portfolio, Chicago, v. 21, n. 1, p. 1-20, 1986.

DEMO, Pedro. Educar pela pesquisa. Campinas: Editora Autores Associados, 1996.

DEWEY, John. The school and society. In: BOYDSTON, Jo Ann (ed.). Early essays and Leibniz's new essays, 1882-1888. Carbondale, IL: Southern Illinois University Press, 1976. (Collected works of John Dewey. The early works of John Dewey, v. 1, 1882 - 1898).

FREIRE, Paulo. Pedagogia do oprimido. Rio de Janeiro: Paz e Terra, 1987.

GARDNER, Howard. Inteligências múltiplas: a teoria na prática. Porto Alegre: Artes Médicas, 1995. 
KNAUSS, Paulo. Sobre a norma e o óbvio: a sala de aula como lugar de pesquisa. In: NIKITIUK, Sonia M. Leite (org.). Repensando o ensino de história. São Paulo: Cortez, 2001. p. 26-46.

ORTEGA Y GASSET, José. Em torno a Galileu. Petrópolis: Vozes, 1989.

PEREIRA NETO, André de Faria. O uso de documentos escritos no ensino de História: premissas e bases para uma didática construtivista. História \& Ensino, Londrina, v. 7, p. 143-165, out. 2001.

PESAVENTO, Sandra Jatahy. História cultural. Belo Horizonte: Autêntica, 2003.

PISTRAK, Moisey M. Fundamentos da escola do trabalho: uma pedagogia social. São Paulo: Expressão Popular, 2000.

RÜSEN, Jörn. El desarrollo de la competencia narrativa em el aprendizaje histórico: una hipótesis ontogenética relativa a la consciencia moral. Propuesta Educativa, Buenos Aires, AR, n. 7, p. 27-36, out. 1992.

SCHMIDT, Maria Auxiliadora; GARCIA, Tânia Maria. A formação da consciência histórica de alunos e professores e o cotidiano em aulas de História. Cadernos CEDES, Campinas, SP, v. 25, n. 67, p. 297-308, set./dez. 2005.

TERRA, Antônia. História e dialogismo. In: BITTENCOURT, Circe. O saber histórico na sala de aula. São Paulo: Contexto, 2004. p. 91-103.

VYGOTSKY, Lev S. A formação social da mente. São Paulo: Martins Fontes, 1984. 